Article

\title{
Deep Contact Strength of Surface Hardened Gears
}

\author{
Alexey Beskopylny ${ }^{1, *(D)}$, Besarion Meskhi ${ }^{2}$, Nikolay Onishkov ${ }^{3}$, Lubov Kotelnitskaya ${ }^{4}$ and \\ Oxana Ananova 5
}

1 Department of Transport Systems, Faculty of Roads and Transport Systems, Don State Technical University, Gagarin, 1, 344000 Rostov-on-Don, Russia

2 Department of Life Safety and Environmental Protection, Faculty of Life Safety and Environmental Engineering, Don State Technical University, Gagarin, 1, 344000 Rostov-on-Don, Russia; reception@donstu.ru

3 Department of Transport Systems and Logistics, Faculty of Transport, Servis and Maintenance, Don State Technical University, Gagarin, 1, 344000 Rostov-on-Don, Russia; onishkova1@yandex.ru

4 Department of Mathematics, Faculty of IT-Systems and Technologies, Don State Technical University, Gagarin, 1, 344000 Rostov-on-Don, Russia; kotelnitskaya@mail.ru

5 Department of Marketing and Engineering Economics, Faculty of Innovative Business and Management, Don State Technical University, Gagarin, 1, 344000 Rostov-on-Don, Russia; o_ananova@mail.ru

* Correspondence: besk-an@yandex.ru; Tel.: +7-863-2738454

Received: 2 April 2020; Accepted: 4 May 2020; Published: 5 May 2020

\begin{abstract}
This article is devoted to the analysis methods for assessing the load capacity of gears hardened by surface chemical-thermal treatment (CTT), which are characterized by structural and chemical heterogeneity. The leading type of failure is determined by several factors, the main of which are the surface and deep layer properties of the material, which fundamentally differ in the energy and structural state. Intercrystalline fracture mechanisms predominate in the surface layers and transcrystalline in the core. For these cases, the classical failure criteria of Mohr, Tresca, and Mises lead to significant errors. Therefore, the bearing capacity of the layer component is investigated by the generalized criterion of the limit state of the Pisarenko-Lebedev structurally inhomogeneous material, considering changes in its plastic properties due to surface hardening. The reliability of predicting the level of bearing capacity of surface hardened steel parts, such as gears, was significantly improved. The influence of the plasticity parameter on the level of bearing capacity for various types of CTT is estimated. Calculations using the presented model show that for alloy steels with a Ni content up to $1 \%$, the safety coefficient can be limited to 1.2 , which will increase the bearing capacity by $25-27 \%$.
\end{abstract}

Keywords: gears; fracture; durability; strength criteria; deep contact strength; chemical-thermal treatment; hardened layer; hardness; plasticity parameter

\section{Introduction}

For high-quality gearboxes with traditional involute gearing that are manufactured and operated in normal operating conditions, the primary indicator of working capacity is surface contact strength [1]. This is logically justified. The surface layers of a machine part during operation are loaded more intensively than internal volumes, and they perceive all the acting loads with their surfaces. Also, any structural component after manufacture has the surface layer and the substrate that fundamentally differs in the energy and microstructural state. Moreover, the material of the surface layer (without additional hardening) has a lower strength relative to the base. Such parts are characterized by surface contact damage or pitting; that is, progressive chipping from small pits to wide shallows with plastic deformation of surfaces.

However, for highly stressed thermo- or chemical-thermo-hardened machine parts, deep contact fractures (DCF) take place. This is a specific type of failure and an independent form of destruction 
with a fundamentally different model of contact fatigue life. The initial pitting is formed due to surface fatigue at a depth of 1 to $20 \mu \mathrm{m}$ [2]. However, the maximum equivalent stresses are localized at a certain depth, and at high contact loads, especially during surface hardening of a part, it is possible to outstrip the development of subsurface defects (Figure 1), both in the hardened layer and in the region of transition to an unhardened core with subsequent separation of the layer.

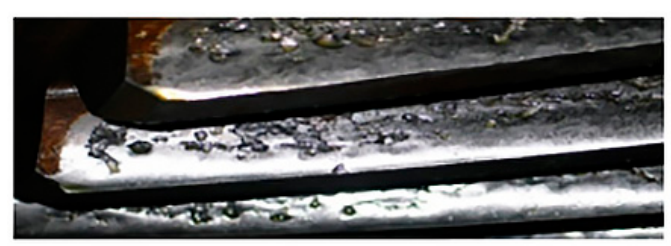

(a)

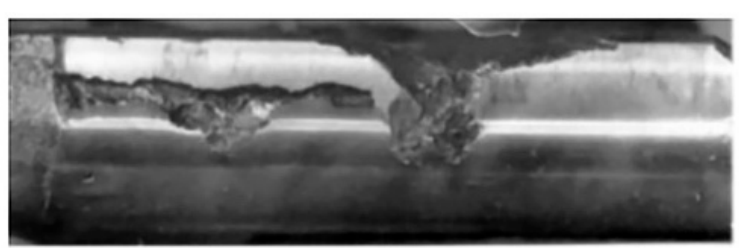

(b)

Figure 1. Contact tooth surface fatigue: (a) surface (pitting); (b) surface and deep, turning into a cleavage.

Both deep and surface processes occur simultaneously, and the leading type of destruction is determined by the number of factors, the main of which are the level of tension and properties of the surface layers of the material. Tobie et al. [3] showed that the material and especially the strength properties at a greater depth of the steel become more critical. They also gave an overview of the main modes of gear destruction due to material fatigue. The underlying load and stress mechanisms were also examined in specific consideration of the size of the gear train, since these considerations mainly determine the required material properties.

However, the deep contact strength (DCS) assessment model itself is not identical to the model of deep contact endurance (durability), but just one of its components. The initial data for the calculations are contacting load, geometric, and tribological characteristics of the contact. These factors determine the initial macro stress state, adjusted by running-in [4]; they are common for evaluating both depth and surface strength.

Specific features of durability under the conditions of DCS are due to thermal (chemical-thermal) processing, a change in the mechanical properties of the hardened layer, and an inevitable consequence is an increase in the density of material defects within the layer. These characteristics determine the limited state and, accordingly, the field of effective stresses, which predicts the occurrence of microcracks. Another critical indicator of longevity is the rate of crack growth. This indicator has been thoroughly investigated. According to Leng et al. [5], the durability of rolling bearings (volume hardening to $\mathrm{H}=60-62 \mathrm{HRC}$ ) does not exceed $2-3 \%$ of the total resource, while the occurrence of primary defects in the sublayer of cemented rollers accounted for the first $10-15 \%$ of their life (before the exit cracks to the surface). Then, a contact fatigue crack begins where the maximum value $\tau_{\text {max }} / H_{V}$ occurs. The influence of factors such as types of steels, the process of steel smelting, cleanliness, fiber orientation, forging coefficient, and negative fatigue strength treatment at rolling contact was investigated Tsushima et al. [6] for rolling bearing steels. Fatigue life during rolling in contact with the steel, which has high purity, increased markedly, and the influence of the orientation of the fibers or processing with a negative impact on the fatigue life during rolling was negligible.

The methodology for calculating gears for contact strength in Russia is carried out on the basis of the standard [7]. The methods apply to power gears of external gearing, consisting of steel gears, the initial circuit of which meets the requirements of GOST 13755, built-in or made in the form of independent units working with grease in a closed case at a peripheral speed of not more than $25 \mathrm{~m} / \mathrm{s}$ in the range of ambient temperatures from minus 40 to plus $100{ }^{\circ} \mathrm{C}$. These methods do not take into account the heterogeneity of the structure of the material during CCT and lead to significant errors.

The microstructure and properties of duplex steel during the plasma carburization procedure at relatively high temperature were studied by Biserova-Tahchieva et al. in [8]. High diffusion of elements and inhomogeneity in a super duplex material were observed. The study was aimed at 
improving the surface corrosion properties and proved to be adequate surface protection from the point of view of corrosion properties.

Special heat treatment and super polishing were applied by Amanov et al. to increase the resistance to bearing fatigue during contact rolling [9]. The improvement in contact strength was confirmed depending on contact stress, surface hardness, and friction before and after treatment with ultrasonic nanocrystalline surface modification. The surface top had a microhardness of $864 \mathrm{PM}$ and decreased to $720 \mathrm{PM}$ at a depth of $2 \mathrm{~mm}$ exponentially.

Carburizing technology is improving. Sugimoto et al., in [10], investigated the effect of the carbon potential in vacuum cementation on the properties of a surface hardened martensitic steel layer for the manufacture of precision gears. The changes in the volume fraction of residual austenite, hardness (HV) and residual stress as a function of depth from the surface in steel, which underwent vacuum cementation and the deposition of fine particles, were studied.

The reaction of carbonized steel $20 \mathrm{CrNi} 2 \mathrm{MoV}$ to cryogenic treatment, including the microstructure and wear resistance, was studied in [11]. Two cryogenic treatment methods, including cryogenic treatment at $-80{ }^{\circ} \mathrm{C}$ and deep cryogenic treatment at $-196^{\circ} \mathrm{C}$, as well as conventional heat treatment were performed after the carburization process. In [12], it was noted that traditional cementation has disadvantages, such as high energy consumption, significant deformation of parts, and an imperfect structure of the cementation layer. The method of preliminary implantation of rare-earth ions was used to catalyze and strengthen the carburized layer of alloy steel 20Cr2Ni4A.

Large plastic deformation mainly contributed to increased hardness and residual compressive stress. A study of the relationship between the surface microstructure and the wear mechanism in the wheel-rail material under various conditions of contact stress was carried out in [13]. It was shown that the thickness of the plastic strain layer and the surface hardness increase with increasing contact stress. Under conditions of high contact stress (1200 MPa), a layer of severe plastic deformation led to the formation of fatigue wear on wheel rails.

Three different types of heat treatment of carburization-high temperature tempering, low temperature tempering, and nitrocarburizing-were applied to martensitic stainless steels in [14]. These steels are attractive for use in bearings due to their high corrosion resistance and surface hardenability due to heat treatment by carburizing. The studies in [13] emphasized the effectiveness of scanning force microscopy for predicting the behavior of bulk corrosion by measuring the difference in surface nanoscale between carbides and the surrounding matrix.

An extensive analysis of the thermochemical treatment of austenitic steels such as nitriding and cementation was carried out Borgioli [15]. The microhardness profiles of AISI 321 samples nitrided by plasma $\left(380^{\circ} \mathrm{C}, 40 \mathrm{~h}\right)$, carburized $\left(470{ }^{\circ} \mathrm{C}, 20 \mathrm{~h}\right)$, and nitrocarbonized (hybrid NTC process) $\left(380^{\circ} \mathrm{C}\right.$, $40 \mathrm{~h}$ ) in depth were presented. The review showed the formation of nitride or carbide precipitation, and the influence of alloying elements present in austenitic stainless steels.

A new surface activation method for low-temperature cementation was presented in Li et al. [16] for AISI-AL-6XN steel. The method involves the removal of passivating surface oxide and a potentially existing highly plastically deformed surface layer and immersion in ethanol and subsequent drying in nitrogen. Cross-sectional optical microscopy of the low-temperature carbonized AISI-AL-6XN showed a well-formed thickness of the heat-strengthened layer.

The structure and mechanical characteristics of coatings and substrates were studied by Adachi et al. [17], who used cold-spray AISI 316L stainless steel coatings to form an austenitic phase with excess dissolved nitrogen (known as S-phase) by plasma nitriding at temperatures below $450{ }^{\circ} \mathrm{C}$. Low-temperature nitriding and carburizing at temperatures below $450{ }^{\circ} \mathrm{C}$ for austenitic stainless steel plates can lead to the formation of an austenitic phase with excess dissolved nitrogen, known as the $\mathrm{S}$ phase. Two types of combined low-temperature plasma treatment to increase the mechanical reliability of the S-phase layer were investigated: (i) sequential and (ii) simultaneous. The profiles of the depth of hardness of the samples obtained by a single nitriding sharply decreased at a certain depth, and the profiles of the samples obtained by combined treatment gradually reduced. 
The results [18] of studies of laser processing of the microstructure and properties of the film fluorosiloxane coating are presented. Test methods for studying the properties of the coating and the structure of the base are obtained. This allowed us to determine the optimal conditions for laser processing were established for film coatings, which opens up new prospects for a higher technical level and increase the service life of friction units $[19,20]$.

Currently, the quality of thermally and chemically-thermally hardened parts (in particular, gears) is evaluated by the surface hardness $H_{0}$, core $H_{K}$, and the thickness of the hardened layer $h_{t}$ (Figure 2) [21]. But due to its "fuzziness", including due to the wide 29-43 HRC allowed interval $H_{K}$, not so full $h_{t}$ is regulated, but the so-called effective $h_{t e}$ thickness of the hardened layer; $h_{t e}$ is the distance along the normal from the surface to the depth with a certain predetermined hardness level $H_{e}$-effective hardness, carbon content or a certain structure. When cementing and nitrocarburizing most often use $H_{e}=550 H_{H V}$, with nitriding $H_{e}=400 H_{H V}$ or $H_{e}=H_{K}+50 H_{H V}$; the surface hardening $h_{t e}$ is defined as the distance to the zone with a semi-martensitic structure, the hardness of which depends on the carbon content, i.e., from a specific steel grade.

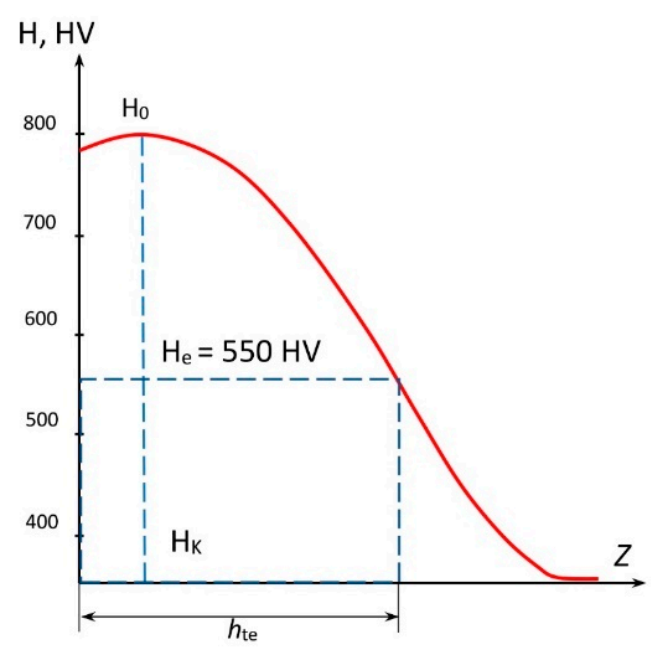

Figure 2. Hardness distribution over the thickness of the hardened (cemented) layer.

Directly adjacent to the surface is the so-called "defective" zone, which is inevitable during CTT: oxides, non-martensitic structures, the dark component (during nitrocarburizing) with reduced mechanical properties; $0<z \leq z_{H_{e}}$-effective zone (it is believed that it determines the level of bearing capacity of the hardened layer; $z_{H_{e}}<z \leq z_{H_{K}}$-sublayer (transition zone).

For traditional involute gears, the rational parameters of the hardened layer are determined mainly empirically. But their distribution to other types of transmission-Wildgaber-Novikov, modified involute (including cylindrical with an increased overlap coefficient, with an increased engagement angle), etc-without the appropriate theoretical justification is illegal, due to the difference in the characteristics of the stress state. Hence, the relevance for heavily loaded programs of predicting the level of DCS based on, at least, phenomenological approaches.

Thus, the aim of this work is to increase the accuracy of predicting the load capacity level of thermally and chemically-thermally hardened gears by the DCS criterion, respectively, reducing the standard safety factors $S_{H}$, which in current methods reach 1.5 , by stress, which is equivalent to an almost threefold decrease in the permissible contact load.

\section{Materials and Methods}

Most of the applied methods for strength calculation of machine parts are based on extensive experimental studies, and most often, plasticity hypotheses are used as criteria. Known models for the evaluation of DCS, a brief summary of which is given below in Table 1, are based on the 3rd and 4th 
hypotheses of static strength, on the hypothesis of orthogonal tangential stresses, as well as on the Gest-Mohr hypothesis. Here is $h_{H}$-the depth of maximum equivalent stresses.

Table 1. Calculation models for assessing deep contact strength.

\begin{tabular}{|c|c|c|c|c|}
\hline No. & $\begin{array}{l}\text { Estimated Effective Stress } \\
\qquad \sigma_{H K e}\end{array}$ & $\begin{array}{l}\text { Ultimate Effective } \\
\text { Stress } \sigma_{\text {HKlime }}\end{array}$ & Formula & Reference \\
\hline 1 & $\begin{array}{c}0.5 \sigma_{K \max } \text { where } \sigma_{K \max } \\
\text { maximum normal contact } \\
\text { stress at the center of } \\
\text { contact ellipse }\end{array}$ & $0.84 H$ & $\begin{array}{l}H_{H B} \leq 350 \mathrm{HB} \\
H_{H V}>350 \mathrm{HV}\end{array}$ & [22] \\
\hline 2 & $\left|\tau_{y z}\right|-0.2\left|\sigma_{z}\right|$ & $1.07 H_{K}$ & $H \leq H_{B} 350$ & [22] \\
\hline 3 & $\left|\tau_{y z}\right|-k\left|\sigma_{z}\right|$ & $0.8 H_{100}$ & $\begin{array}{l}k=0.25 \text { at } H \leq 600 H_{100} \\
k=0.40 \text { at } H \leq 600 H_{100}\end{array}$ & [19] \\
\hline 4 & $\left|\tau_{y z}\right|-Y_{s}\left|\sigma_{z}\right|$ & $3.15\left(H_{H V}\right)^{0.616} K_{c}$ & $\begin{array}{c}K_{c}, Y_{s} \text {-Figure } 4.1 \text { and } 4.2 \\
\text { reference [23] }\end{array}$ & {$[23,24]$} \\
\hline 5 & \multirow{2}{*}{$\begin{array}{c}0.5\left(\sigma_{1}-\sigma_{3}\right), \text { where } \sigma_{1}, \sigma_{3} \\
\text { principal stresses }\end{array}$} & $1.00 H_{100}$ & - & [25] \\
\hline 6 & & $1.00 H_{H B}$ & - & [26] \\
\hline 7 & $\sigma_{K \max }$ & $3.6 H$ & $\begin{array}{c}H=H_{K} \text { at } h_{H}>h_{t} \\
H=H_{e} \text { at } h_{H} \leq h_{t} \\
H_{e}=H_{\left(h_{H}+0.2\right)}\end{array}$ & {$[19,20]$} \\
\hline 8 & $\sigma_{K \max }$ & $4.5 \mathrm{H}$ & $\begin{array}{c}H=H_{K} \text { at } h_{H}>h_{t} \\
H=H_{e} \text { at } h_{H} \leq h_{t} \\
H_{e}=H_{0.7 b_{H}^{\prime}} \\
\text { where } b_{H} \text {-half-width of } \\
\text { the linear contact pad. }\end{array}$ & [7] \\
\hline 9 & $\begin{array}{l}\max \left(\tau_{\max } / H_{H V}\right) \\
\max \left(\tau_{x y} / H_{H V}\right) \\
\max \left(\sigma_{i} / H_{H V}\right) \\
\end{array}$ & - & - & {$[2,5]$} \\
\hline
\end{tabular}

The models in positions 1 and 2 (Table 1) mainly evaluate the strength of the core and the adjacent layer section using the dependencies of the mechanical characteristics of steels of medium viscosity with a hardness of up to $350 \mathrm{HB}$. The field of their rational use is the types of CTT, in which relatively thin diffusion layers (nitriding) are formed. The model in pos. 3 (Table 1) is not limited to segments of medium hardness, and the difference in the strength indices of the material is taken into account by the coefficient. However, at $k=0.4$ for layers with $H>600 H_{100}$ at depths up to $0.4 b_{H}$ (where $b_{H}$ is the half-width of the strip for linear contact or the minor axis of the contact ellipse for theoretically point), the effective stress $\sigma_{e}<0$, and the model is not applicable. In addition, due to the discreteness of the coefficient $k$ in the region $H=600 H_{100}$, there is a "jump" in strength indicators that contradict the logic.

The methods in pos. 4, 7 and 8 (Table 1) are focused on the evaluation of DCS at a depth of maximum effective stresses. In [21], the results of the estimation of the DCS level according to the GOST 21354-87 method [7] of a number of well-known experiments are shown, which show that the DCS can occur at various depths and with calculated safety factors that significantly exceed the standard ones, i.e., guaranteeing no failure according to this criterion. The models in pos. 9 are limited to the qualitative determination of the potentially dangerous zones of the hardened layer-the so-called "risk zones" corresponding to the maximum amplitudes of the ratios of equivalent (according to the chosen criterion) stresses to Vickers hardness. A qualitative definition of "risk zones" is quite satisfactory.

Common to all models except for pos. 4 (Table 1) is a postulation of a linear relationship between the strength of the material and its hardness for the entire layer. However, the use of different hardness scales in itself already indicates the absence of an established view of hardness as a sufficient indicator of the strength of the material, especially when $H_{H V}>(450-500) \mathrm{HV}$ [27]. 
Hardness is the most important characteristic of the strength of steel and, at the same time, the most easily controlled material parameter. This property is correct for normalized and improved steels, but insufficient for thermally hardened. So, the limits of contact endurance of steel parts are determined by piecewise linear dependences on hardness: according to ISO 6336 or according to GOST 21354-87. Several standards-AGMA, ISO standards-have very high weight coefficients of the influence of hardness, limited to the level of 58-62 HRC because with a further increase in hardness, the experimental data are contradictory. This fact can be confirmed by graphs of changes in the mechanical characteristics of hardened carbon steels [28], which show a decrease (or, in any case, stabilization) in the tensile and compressive strengths.

The nature of the fracture changes from viscous intercrystalline $H<H_{B}=450$ to mixed or brittle transcrystalline (depending on the rigidity of the load). There is a further increase in hardness, differences in the range of yield, and tensile and compressive strength. The danger of brittle fracture is not in dispute. However, the prediction of this type of failure is still mainly of a qualitative nature.

With increasing embrittlement, the role of shear stresses in the process of fracturing of viscous materials decreases. With equal hardness, thermally or chemically-thermally hardened steel alloyed with nickel surpasses its nickel-free analogue in strength and durability; a similar effect occurs with nitrocarburizing (compared with equivalent cemented layers). The presence of nickel in the first case and nitrogen (in solid solution and nitride phase) in the second helps to stabilize the fine-grained structure of the material, increasing its plastic properties $[29,30]$. These factors are well-known in quality and are corrected in practice by introducing a set of correction factors that take into account the properties of a particular material, the type and conditions of hardening thermal (chemical-thermal) processing, etc., i.e., the results of experience and expensive experiments.

CTT leads to the formation of a surface layer with significant structural heterogeneity (from the hypereutectoid at the surface to the hypereutectoid during the transition to the core) and a change in its chemical composition. Accordingly, the influence of factors responsible for the destruction process also changes. Under such conditions, foci of DCS can also occur at great depths (including in the transition zone), when the intensity of the decrease in the strength properties of the material is ahead of the intensity of the decrease in the existing stresses. Moreover, the possibility of parallel development of DCS at several depth levels sufficiently remote from each other is not ruled out [26]. Thus, the evaluation of DCS should be made over the entire thickness of the hardened layer. But this is possible only if there is more or less reliable information about the change in the strength characteristics of the layer by its thickness. Using the Mises and Tresca criteria, orthogonal tangential stresses, which indicate only the possibility of the appearance of plasticity, is incorrect, because the question of whether microplastic changes are a measure of contact fatigue is not yet resolved [31,32]. Under these conditions, hardness ceases to be a sufficient strength characteristic, and other indicators, as well as possible structural defects, the probability of which increases as a result of thermal or chemical-thermal treatment, must be taken into account. The refinement of quantitative estimates of strength is related to the plastic properties of the material and their change during thermal and chemical-thermal treatment. The most promising in such conditions is the use of generalized criteria for the limiting state, taking into account the influence of both tangential and normal stresses.

The use of the Guest-Mohr criterion with a constant coefficient of influence of normal stresses is correct mainly for sufficiently homogeneous structures [20,22]. Of course, this was a step in the right direction, with a structural coefficient variable in the hardness range (500-800), taking into account the influence of the bainitic and carbide phases $[23,24]$. However, the most promising, in our opinion, is the Lebedev-Pisarenko criterion for structurally heterogeneous material [33,34], used in [27-29], related, in particular, to the prediction of the occurrence of deep contact fractures (DCS) of Novikov's surface hardened gears, for which well-known recommendations for involute transfers were not acceptable. 


\section{Results and Discussion}

\subsection{Lebedev-Pisarenko Criterion}

Equivalent stresses, according to this criterion, have the form:

$$
\sigma_{e}=\chi \sigma_{i}+(1-\chi) \sigma_{1} A^{1-\frac{\left(\sigma_{1}+\sigma_{2}+\sigma_{3}\right)}{\sigma_{i}}} \leq \sigma_{e+}
$$

where $\sigma_{1}, \sigma_{2}, \sigma_{3}$ are principal stresses; $\sigma_{i}$ is the intensity of octahedral stresses, under the plane stress $\sigma_{i}=\sqrt{\left(\sigma_{1}^{2}-\sigma_{1} \sigma_{2}+\sigma_{2}^{2}\right)} ; \sigma_{\mathcal{e}}$ is the ultimate equivalent stress at $\sigma_{1}>0 ; \chi=\sigma_{\mathcal{e}} / \sigma_{\mathcal{e}}$ is the plasticity parameter of the material, taking into account the degree of influence of shear deformations on its microfracture; $\sigma_{e+}, \sigma_{e-}$ are the failure stress (fracture) of the material during uniaxial tension and compression, respectively; and $A$ is the statistical defect parameter; for hardened steels, $A=0.7-0.8$.

For ductile materials, $\sigma_{\mathcal{e}} \approx \sigma_{e_{-}}, \chi \rightarrow 1$, and Formula (1) reflects the Mises criterion. For absolutely brittle materials $\chi \rightarrow 0$, a transition to the criterion of maximum normal stresses takes place. Since Equation (1) is resolved concerning tensile stresses $\sigma_{1}<0$, for contact problems the exponent for the defectiveness parameter should be taken in its absolute value, and the limiting values of the effective stresses can be presented in the form:

$$
\sigma_{e+}=\chi \sigma_{H P} k_{e}
$$

where $\sigma_{H P}$ is the allowable normal contact stress, and $k_{e}=\sigma_{e} / \sigma_{e m a x}$ is the equivalence coefficient.

Thus, both the left and right sides of (1) are functionally dependent on the parameter $\chi$. If the criteria of plasticity operate only with the components of the stress tensor, then the use of the criteria of the limiting state requires knowledge of the value of the parameter $\chi$, as well as the nature of its change depending on the chemical composition of the steel and the type of hardening. It is known that the value $\chi$ varies from 0.9 to 1.0 for thermally improved structural steels to 0.5 to 0.7 for volume-hardened medium and high carbon, the mechanical characteristics of which were given in [21].

The values of the equivalence coefficient are determined by the parameter values and the nature of the contact:

for linear contact:

$$
k_{e}=0.62574(\chi-0.11128)
$$

for elliptical contact:

$$
k_{e}=0.58270 \chi \ln \left(0.60223 K_{E l}+2.8984\right)-0.062
$$

where $K_{E l}$ is the ellipticity coefficient, the ratio of the minor axis of the contact ellipse to the major (at $K_{E l} \leq 0.45$ the differences $k_{e}$ are insignificant).

The influence of the plasticity parameter on the strength level is investigated through the safety factor $S_{K}$ is the ratio of current and allowable stresses:

$$
S_{K}=\frac{\chi \sigma_{H P} k_{e}}{\chi \sigma_{i}+(1-\chi) \sigma_{1} A^{1-\frac{\left(\sigma_{1}+\sigma_{2}+\sigma_{3}\right)}{\sigma_{i}}}}
$$

Within the hardened layer, a change in the structures occurs from hypereutectoid in the near-surface zone to hypereutectoid in the transition zone. In accordance with this, the properties of the hardened layer were taken to be similar to the properties of hardened steels with a similar chemical composition: high carbon for the effective zone, medium structural carbon for the transition [21]. The core of the part retains the properties of thermally advanced steel. Within the framework of the proposed model, a change in these properties is taken into account by a change in the parameter $\chi$.

A comparison, within the limits of the alternative to the application of processes of cementation and nitrocarburizing, shows that nitrocarburizing provides a higher level of bearing capacity. 
The difference in contact fatigue life is multiple [35]. However, in the practice of engineering calculations, both processes are considered equivalent. However, at a hardness identical and constant across the thickness of the specimen (steel 12Kh2N3A, C 0.09-0.15\%, Ni 3.25-3.65\%, Cr 1.25-1.65\%, Si $0.17-0.37 \%$, Mn $0.3-0.6 \%$ ), the $\sigma_{e+}$ of the samples subjected to nitrocarburizing is $10-12 \%$ higher than cemented ones [36,37], which, in the absence of data on the corresponding increase in $\sigma_{e-}$ allowed, in the first approximation, take at the hardness level $850 H_{H V}$ the values of the ductility parameter $\chi=0.6$ (cementation of nickel-free steels) and $\chi=0.68-0.7$ (cementation of nickel-containing steels and nitrocarburizing). In the absence of additional information, the change in the plasticity parameter in the interval $400-850 H_{H V}$ was assumed linear:

$$
\chi= \begin{cases}-0.89 H_{H V} \times 10^{-3}+1.356, & \left(\chi_{\min }=0.60\right) ; \\ -0.71 H_{H V} \times 10^{-3}+1.284, & \left(\chi_{\min }=0.68\right)\end{cases}
$$

at $H \leq 400 \mathrm{HV}, \chi=1$.

Concerning the calculations of DCS, Expression (2) takes the form:

$$
\sigma_{e}=\sigma_{H K} \leq \sigma_{H K P e} ; \quad \sigma_{H K P e}=\frac{\sigma_{H K l i m e}}{S_{H K}} ;
$$

where $S_{H K}$ is a complex of factors affecting the load capacity of the contact, but not related to the calculation model.

Based on (1), (2) and (5), the permissible equivalent stress is:

$$
\sigma_{H K P e}=\chi(\chi-0.11128) H_{H V} Z_{L K} K_{1} K_{2} K_{3} K_{4} K_{5} K_{6}
$$

where $Z_{L K}=\left(10^{7} / N_{E K}\right)^{1 / q}$ is the durability coefficient based on $N=10^{7}$ loading cycles; $K_{1}$ is a coefficient considering the type of contacting: $K_{1}=2.05-2.15$ with linear contact and $K_{1}=2.55-2.70$ with point contact, $K_{2}$ is a coefficient considering the number of potentially dangerous areas; and the coefficient $K_{3}$ considers the influence of the external tangential load, caused primarily by friction forces. This effect decreases significantly with distance from the surface, and for involute gears with $z \geq 0.2 b_{H}$ and for Novikov transfers with $z \geq 0.3 b_{H}$ (assuming an elliptical contact), the influence of the external tangential load is negligible and is not taken into account in further calculations: $K_{3}=1.0$ [21,22]. Regarding the remaining coefficients, $K_{4}$ considers the approximation error of the real tooth surfaces with second-order surfaces; $K_{5}$ represents the quality of the material and CTT; and $K_{6}$ represents the dispersion of the material properties in the layer, which are considered below.

Taking into account the influence of the plastic properties of the material of the layer made it possible to increase the level of forecasting of the level of the load capacity of CTT of hardened parts.

It is confirmed that in the conditions of contact interaction for involute gears, an increase in hardness higher than 650-700 HV practically does not lead to an increase in the contact-fatigue durability of working surfaces, and when $H>800 \mathrm{HV}$, a decrease can even be expected [2,29,38]. When evaluating the DCS of carbonized rollers [26], the interesting fact is the decrease in the strength of the CC-60 samples compared to the CD-30 when the layer hardness increased at the calculated depths: $820-835 \mathrm{HV}$ in the CC-60 samples and in the CD-30 samples, although it is logical to expect the opposite.

With a decrease in the parameter $\chi$, the depth of the maximum equivalent stresses and the relative stress $\sigma_{e} / \sigma_{e \max }$ increase, propagating both in-depth and on the periphery of the contact area.

In the case of a theoretical point contact, the maximum equivalent stresses shift to the boundary of the instantaneous contact spot-the net shear zone, already initiating alternative types of failure (kinks, chips), which systematically occurred during bench tests of Novikov gears [3,27-29]. 


\subsection{Hardness Distribution over the Thickness of the Hardened Layer}

Hardness is the most accessible characteristic of steel strength for monitoring, respectively, the quality of the hardened layer, which is largely estimated by the distribution of hardness over the thickness of this layer (Figure 2), using the main controlled parameters of the layer: $H_{0}, H_{K}$, $h_{t e}$. However, although the total thickness of the layer $h_{t}$, due to "blur", is usually not controlled, the standard [6] recommends the dependence of the determination of hardness at a depth of " $z$ ":

$$
H_{z}=H_{0}\left\{\left[\left(\frac{H_{0}}{H_{K}}\right)-1\right]\left[\left(\frac{z}{h_{t}}\right)^{2}+1\right]\right\}^{-1}, \quad z \leq h_{t}
$$

However, the analysis of experimental data, for example [2], convincingly showed that close values of $H_{0}, H_{K}, h_{t}$ do not yet guarantee the "equivalence" of the layers. The approximating function should be insensitive to fluctuations (within the limits of the natural spread and accuracy of the measurement) over most of the interval, passing through the control point $\left(h_{t e}, H_{e}\right), \frac{d H(z)}{d z}=0$, at $z=h_{t}$.

According to the results of the analysis of experimental data, the dependence [27] was obtained as an approximating one:

$$
H_{Z}=\left(H_{0}-H_{K}\right)\left[\frac{h_{t}-z}{h_{t}-h_{0}} \exp \left(\frac{z-h_{0}}{h_{t}-h_{0}}\right)\right]^{B}+H_{K}, \quad z \leq h_{t}
$$

$B=\ln \left(\frac{H_{0}-H_{K}}{H_{e}-H_{K}}\right) \cdot\left(\ln \frac{h_{t}-h_{0}}{h_{t}-h_{t e}}-\frac{h_{t e}-h_{0}}{h_{t}-h_{0}}\right)^{-1}$.

When cementing steels for general engineering purposes, the best agreement with experimental data was obtained at $H_{e}=550 \mathrm{HV}$; when cementing heat-resistant steels, and during nitrocarburizing, it is advisable to take $H_{e}=610 \mathrm{HV}$. An example of using dependencies (7) and (8) according to experimental data $[23,24]$ is shown in Figure 3.

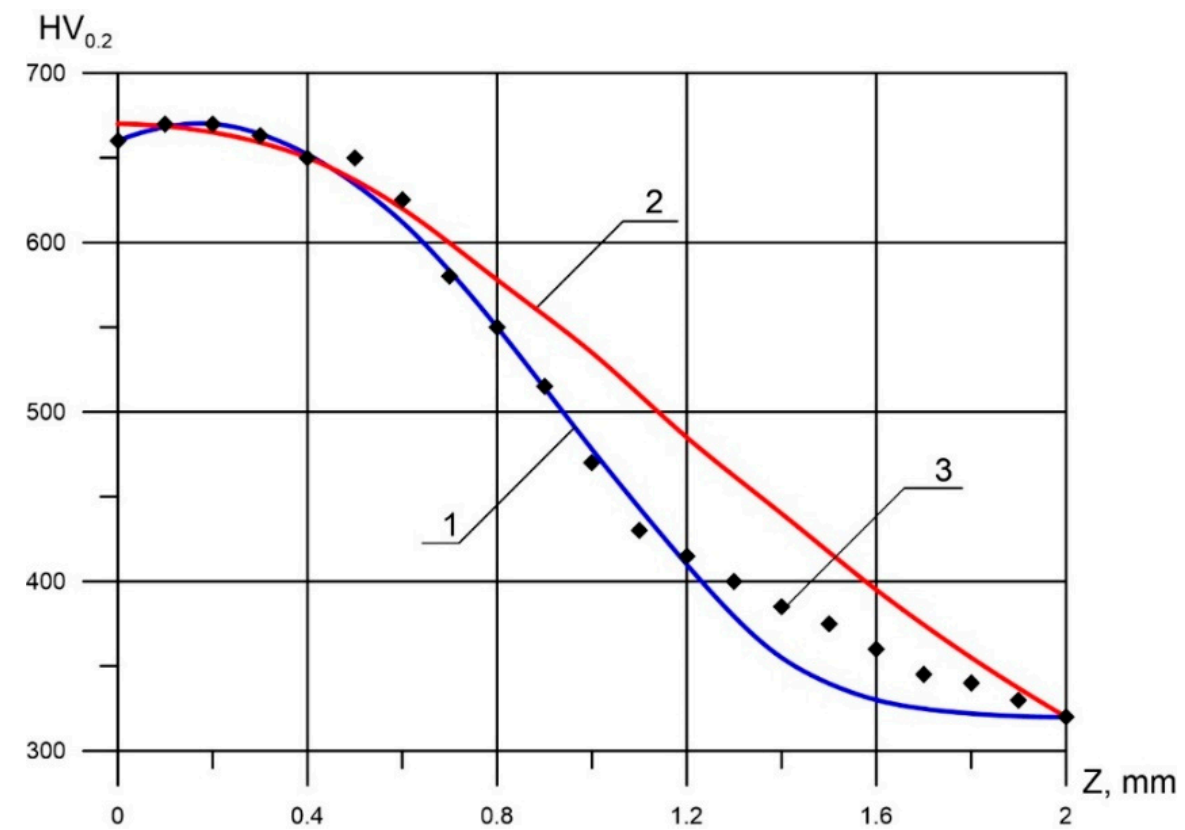

Figure 3. The distribution of hardness over the thickness of the hardened layer of steel 20XH3A after cementation. Layer options: $H_{0}=680 \mathrm{HV} ; H_{K} \approx 320 \mathrm{HV} ; h_{0}=0.1 \mathrm{~mm} ; h_{t e}=0.8 \mathrm{~mm} ; h_{t} \approx 2.0 \mathrm{~mm}$. 1 -distribution according to (8); 2-according to (7); 3-experimental data.

Novikov's nitro-cemented gears were bench tested at the IzMSK Ltd. company (Izhevsk, Russia) [27]. Although all the samples were made of steel of the same batch, and they passed CCT simultaneously, the dispersion of hardness values reached $150 \mathrm{HV}$ within one tooth and $250 \mathrm{HV}$ for the same points of 
different samples. The analysis of 14 samples showed an almost identical prediction of the distribution of hardness according to (8), and the results of statistical processing with a probability of 0.9 .

\subsection{Gear Life Ratio}

In the field of limited durability, the equation of the stress-life curve is $\sigma^{q} N=$ const, where $\sigma$ is the maximum stress in the load cycle, and $N$ is the number of cycles to failure. When calculating the strength of the working surfaces of the teeth, the coefficient $q$ is most often taken as $q=6$. However, when evaluating the DCS of gears, recommendations for the designation of the exponent $q$ vary significantly from $5[23,24]$ to 18 [22]. In experiments with cemented rollers [2], the exponent ranged from $q=8$ to 30 (but results predominantly prevailed at $q>17$ ). Some experimental results are given below [2] (Figures 4 and 5). Figures $4 \mathrm{a}$ and $5 \mathrm{a}$ show the distribution of hardness over the thickness of the layer. Thickened lines in the graphs show the actual destruction zones. Figures $4 \mathrm{~b}$ and $5 \mathrm{~b}$ show Wöhler lines in logarithmic coordinates, where $\sigma_{k \max }$ is the maximum normal contact stress in the center of the contact area.

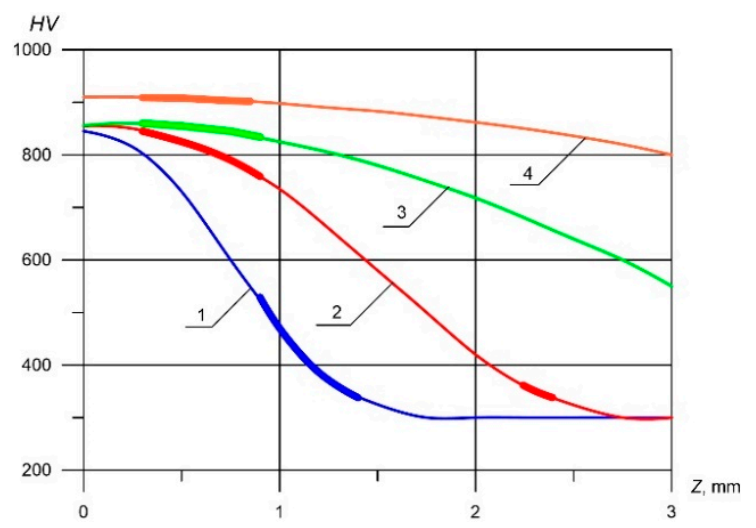

(a)

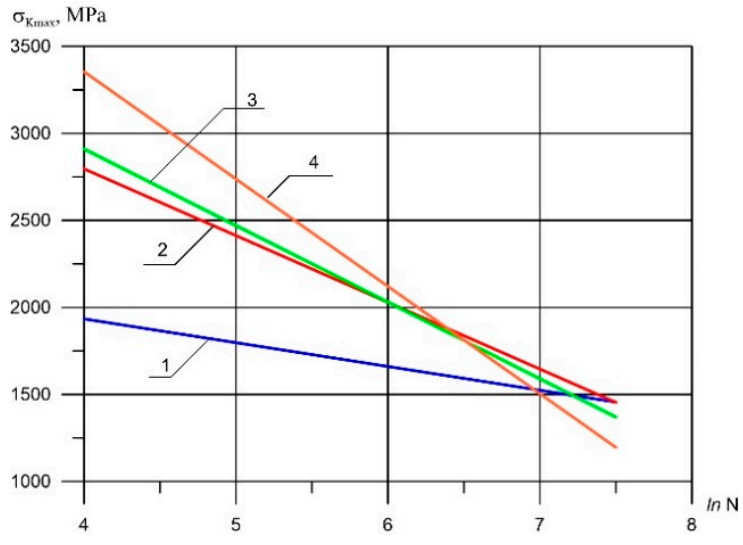

(b)

Figure 4. The contact fatigue life of S-120 samples: (a) the distribution of hardness over the thickness of the hardened layer and the actual areas of failure (highlighted); (b) the Wöhler lines; (1) CA-120; (2) CB-120; (3) CC-120; (4) CD-120.

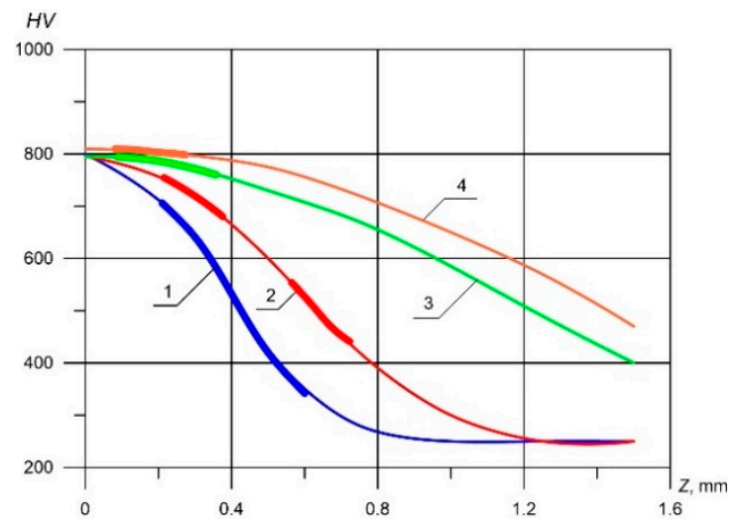

(a)

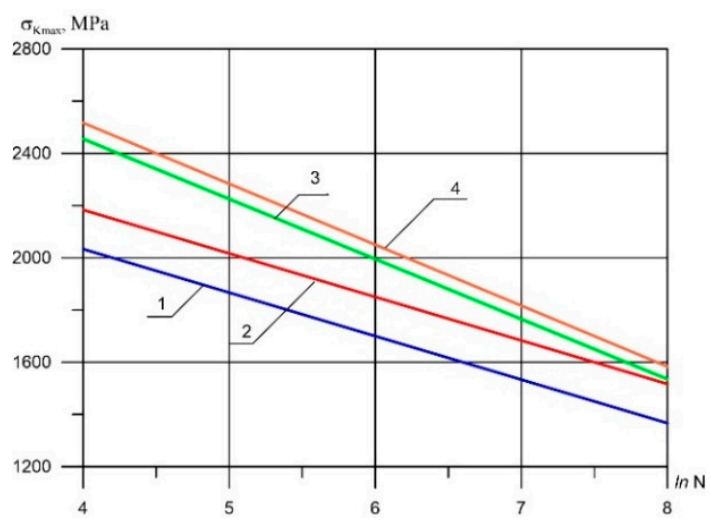

(b)

Figure 5. The contact fatigue life of S-30 samples: (a) the distribution of hardness over the thickness of the hardened layer and the actual areas of failure (highlighted); (b) the Wöhler lines; (1) CA-30; (2) CB-30; (3) CC-30; (4) CD-30.

C-120 Rollers $D=120 \mathrm{~mm}$. The lower boundary of the $z_{p}$ of samples CA-120 destruction was at depths (1.4-1.7) $b_{H}$ with hardness $H=300-320 \mathrm{HV}$; for samples C-120 and CD-120, at depths $(0.45-0.85) b_{H}$ at $H>900 \mathrm{HV}$ for CD-120 and $H>830 \mathrm{HV}$ for CC-120. DCS regions took place at 
two depth levels: (1) in the sublayer $z_{P}=(2.26-2.7) b_{H}$ with $H<350 \mathrm{HV}$; (2) in the effective zone $z_{P}=(0.35-0.65) b_{H}$ with $H=810-830 \mathrm{HV}$.

The exponent $q$ for CA-120 is $q=23.67$; for CB-120, SS-120, CD-120 $q=11.31, q=9.07$ and $q=7.02$, respectively. The sharp difference in $q$ between the CA-120 samples from the rest is possibly a consequence of more energy-intensive transcrystalline fracture, as indicated above. However, for C-30 rollers (Figure 4) with destruction both in the effective zone and in the sublayer, and at two levels, the indices did not differ significantly from 17.40 to 21.43 and for SA-30 with destruction only in the sublayer $(H<420 \mathrm{HV})$ and for CD-30 with destruction only in the effective zone $(H>770 \mathrm{HV})$ practically coincided.

In $[23,24]$, at $N<2 \times 10^{7}$ the values $q \approx 6$ were obtained, which was used in assessing the durability by the criterion of DCS. But with $\sigma_{k \max }=1832 \mathrm{MPa}$ and an operating time up to $5.3 \times 10^{5}$ cycles, nitro-cemented cylindrical gears $m=6.0$ of the basic design of the Kirovets tractor failed according to the DCS, while for geometrically modified gears (which led to a decrease in $\sigma_{k \max }$ of $5.1 \%$ to $1743 \mathrm{MPa}$ ) with an increase of more than 1.5 times, the cause of failure was surface chipping [25]. If $q \approx 6$ remained, the probability of the leading influence of DCS would not have changed.

The available information makes it possible, as a first approximation, to estimate the exponent of the Wöhler line of the hardened layer at $q=5-10$ for $H>750 \mathrm{HV}$ and $\mathrm{HV}$ of the estimated durability up to $N_{P}=(1-2) \times 10^{7}$ loading cycles. At a lower hardness, $q>17$ can be recommended. The number of cycles corresponding to the endurance limit according to the HCP criterion $N_{H k l i m}$ is not determined, but at $N>N_{P}$ surface chipping became the leading one. So, as in [23], unpolished involute gears of general-purpose gearboxes (steel 25KhGM, C 0.23-0.29\%, Si 0.17-0.37\%, Mn 0.9-1.2\%, Cr 0.9-1.2\%, Ni $0.3 \%$, CCT nitrocarburizing up to 56-58 HRC, accuracy 10-9-9 according to GOST 1643-81) at $\sigma_{H} \leq 1400 \mathrm{MPa}$, and gears with polished teeth operating in favorable elastic-hydrodynamic lubrication mode at $\sigma_{H}>1500-1600 \mathrm{MPa}$ were affected by progressive pitting already in the early stages of operation, although alternative types of failure were detected ahead of schedule [28,29].

Novikov gears with an initial geometry of the GOST 30224-96 type show a load capacity of at least $2-3$ times the contact above the involute analogs. With torques on the drive shaft $T_{1}=1500-2000 \mathrm{~N} \cdot \mathrm{m}$ and calculated maximum contact stress $\sigma_{H \max }$ up to $2150 \mathrm{MPa}$, not a single case of pitting was recorded. But this only increases the relevance of predicting the durability of Novikov gears according to the DCS criteria.

In further calculations, the exponent $q=20$ and $Z_{L K}=\left(\frac{10^{7}}{N_{E K}}\right)^{0.05}$ was adopted.

\subsection{Effect of the Number of Potentially Dangerous Areas}

As mentioned above, in several cases, along with "regular" fractures in the effective zone, there were recorded cases of cracks at depths $z=(3-5) b_{H}$ with hardness $260-400 \mathrm{HV}$, where the acting stresses by any criteria are entirely insignificant. At the same time, there are many experiments where the same material of the same hardness withstood more than one and a half (overstress) overload. In the framework of the existing models for estimating DCS, this effect cannot be explained. The presence of a second "risk zone" significantly reduced the level of contact ability. It was not possible to quantify the phenomenon. In many cases, the estimated safety factor $S_{K} \gg 1$. However, the forecast was qualitatively confirmed according to the local maxima of the amplitudes of the ratios of equivalent stresses to Vickers hardness (position 9 of Table 1). In Formula (6), the influence of risk zones is taken into account by the coefficient $K_{2}: K_{2}=1.0$ in the presence of one zone; $K_{2}=0.85-0.90$ with two zones.

\subsection{Effect of the Approximation Error of Real Surfaces by Second-Order Surfaces}

The load distribution over the real contact area in Novikov gears is somewhat less favorable than when approximating this area with an ellipse. In the absence of running-in, the difference in the bearing capacity indices according to the Cod and Mises criteria reaches $10 \%$ on the contact surface and decreases with increasing depth. The running-in significantly changes the conditions of contact. The contact spot in the running-in process spread in height from $15 \%$ to $20 \%$ of the active profile to 
$60 \%$ to $80 \%$. The difference in the absolute maxima of the criterion stresses does not exceed $2 \%$. We can recommend: $K_{4}=1.0$ for involute gears and $K_{4}=0.98$ for Novikov gears according to GOST 30224-96.

3.6. The Influence of Material Quality and the Dispersion of the Mechanical Properties of the Material in the Hardened Layer

The influence of material quality is taken into account by the coefficient in accordance with the recommendations [4]:

$$
K_{5}=\left\{\begin{array}{l}
0.90-0.95-\text { carbon and low-alloy steel without Ni; } \\
0.95-1.05-\text { alloy-steel Ni } 1 \% \\
1.00-1.10-\text { Cr,Ni alloy-steel. }
\end{array}\right.
$$

The inevitable dispersion of the mechanical properties of the material in the hardened layer is recommended to be taken into account by a coefficient with lower values in the absence of automatic control of the CCT process.

\section{Model Analysis}

The correspondence of the proposed model with the known experimental data and alternative calculation methods for checking the correctness is estimated. As an alternative, the following were analyzed: (1) qualitative-according to the criteria of local maxima; (2) quantitative-by the criterion of maximum tangential stresses. Alternative methods were selected from the condition of the possibility of estimating DCS within the entire hardened layer.

In Figures 6 and 7 and in Tables 2-5, examples of the evaluation of DCS of carbonized rollers made of chromium-molybdenum steel SCM2 $[2,38]$ based on the described methodology are shown. In the tables, in addition to the previously indicated, the following notations are accepted: $z$-estimated depth; $H_{z}$-hardness at the calculated depth (in the column of Tables 3 and 5 above the line $H V_{1}$ Vickers hardness, and under the line Brinell hardness $\mathrm{HB}) ; z_{0}=z / b_{H}, k_{\min }, k_{\max }$ - the minimum and maximum values of the product of the coefficients $Z_{L K} K_{1} K_{2} K_{3} K_{4} K_{5} K_{6}$ of allowable stresses; $\sigma_{K H e}\left(\tau_{\max }\right)$-the estimated safety factor by the criterion of maximum tangential stresses [2]. Dimensions: linear in mm; stress in $\mathrm{MPa}$; and hardness of samples at design depths according to graphs [2] and formula (8).

\subsection{Sample CD-30}

Initial data (Table 2): $R_{1}=R_{2}=15 \mathrm{~mm}$ rollers, cycle life $N=1.9 \times 10^{6}$ at $\sigma_{\max }=2011 \mathrm{MPa}$, fracture depth $0.10-0.35 \mathrm{~mm}$, fatigue curve degree indicator $q=22$ (according to experimental data at five loading levels). Figure 6 shows a microsection of fracture of a sample as a result of deep contact stresses. It can be seen that a crack was formed below the surface approximately at $0.15 \mathrm{~mm}$, and pits and detrusions attended its exit to the surface. Tables 3 and 5 show DCS indicators of sample CD-30 and CB-60. Here, $z_{0}=z / b_{H}$ is the depth normalized by the half-width of the contact line.

Table 2. Initial data for deep contact strength (DCS) accessing of sample CD-30

\begin{tabular}{cc}
\hline$H_{0}, \mathrm{HV}$ & 795 \\
$H_{K}, \mathrm{HV}$ & 260 \\
$H_{e}, \mathrm{HV}$ & 550 \\
$h_{0}, \mathrm{~mm}$ & 0.00 \\
$h_{t e}, \mathrm{~mm}$ & 1.08 \\
$h_{t}, \mathrm{~mm}$ & 3.20 \\
$b_{H}, \mathrm{~mm}$ & 0.2690 \\
$\sigma_{k \max }, \mathrm{MPa}$ & 2011 \\
$k_{\min }$ & 2.0400 \\
$k_{\max }$ & 2.3600 \\
\hline
\end{tabular}




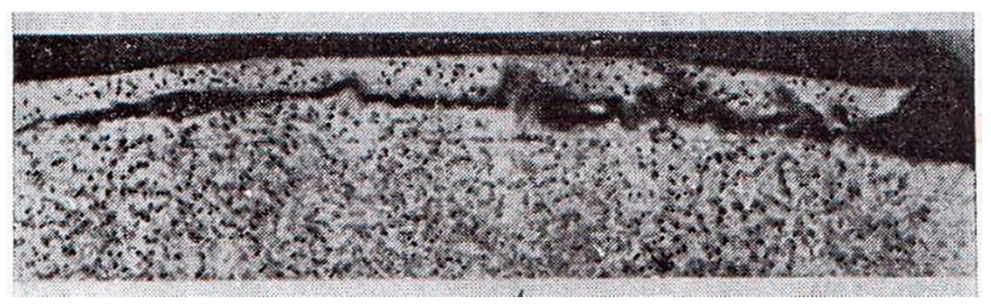

Figure 6. Cross microsection of sample CD-30.

Table 3. DCS indicators of sample CD-30

\begin{tabular}{|c|c|c|c|c|c|c|c|c|c|}
\hline No. & $z_{0}$ & $z$ & $H_{Z}(\mathrm{HV} / \mathrm{HB})$ & $\sigma_{i} / H_{Z}$ & $x$ & $\frac{\sigma_{e}}{\sigma_{k \max }}$ & $\begin{array}{c}\sigma_{K H e} / \sigma_{k \max } \\
\min / \max \end{array}$ & $\begin{array}{c}S_{K H e} / \sigma_{k \max } \\
\min / \max \end{array}$ & $\begin{array}{c}\sigma_{K H e} / \sigma_{k \max } \\
\left(\tau_{\max }\right)\end{array}$ \\
\hline 1 & 0.10 & 0.03 & $795 / 622$ & 1.0120 & 0.649 & 0.232 & $0.281 / 0.325$ & $1.21 / 1.40$ & 1.33 \\
\hline 2 & 0.20 & 0.05 & $794 / 622$ & 1.0987 & 0.649 & 0.251 & $0.281 / 0.325$ & $1.12 / 1.30$ & 1.23 \\
\hline 3 & 0.30 & 0.08 & 794 & 1.2088 & 0.650 & 0.274 & $0.282 / 0.326$ & $1.03 / 1.19$ & - \\
\hline 4 & 0.40 & 0.11 & $792 / 620$ & 1.3044 & 0.651 & 0.295 & $0.282 / 0.326$ & 0.96/1.11 & 1.15 \\
\hline 5 & 0.50 & 0.13 & 791 & 1.3729 & 0.652 & 0.314 & $0.283 / 0.327$ & $0.90 / 1.04$ & - \\
\hline 6 & 0.60 & 0.16 & $789 / 619$ & 1.4116 & 0.654 & 0.329 & $0.284 / 0.328$ & $0.86 / 1.00$ & 1.03 \\
\hline 7 & 0.70 & 0.19 & 787 & 1.4257 & 0.655 & 0.337 & $0.285 / 0.329$ & $0.84 / 0.98$ & - \\
\hline 8 & 0.80 & 0.22 & $785 / 618$ & 1.4224 & 0.658 & 0.341 & $0.286 / 0.331$ & $0.84 / 0.97$ & 0.99 \\
\hline 9 & 0.90 & 0.24 & 782 & 1.4044 & 0.660 & 0.340 & $0.287 / 0.332$ & $0.85 / 0.98$ & - \\
\hline 10 & 1.00 & 0.27 & $779 / 615$ & 1.3790 & 0.663 & 0.337 & $0.289 / 0.334$ & $0.86 / 0.99$ & 1.03 \\
\hline 11 & 1.10 & 0.30 & 775 & 1.3463 & 0.666 & 0.331 & $0.291 / 0.336$ & $0.88 / 1.01$ & - \\
\hline 12 & 1.20 & 0.32 & $771 / 611$ & 1.3112 & 0.669 & 0.325 & $0.292 / 0.338$ & $0.90 / 1.04$ & 1.07 \\
\hline 13 & 1.30 & 0.35 & 767 & 1.2738 & 0.673 & 0.317 & $0.294 / 0.341$ & 0.93/1.07 & - \\
\hline 14 & 1.40 & 0.38 & 763 & 1.2391 & 0.677 & 0.310 & $0.296 / 0.343$ & $0.96 / 1.11$ & - \\
\hline 15 & 1.50 & 0.40 & $758 / 608$ & 1.2018 & 0.681 & 0.301 & $0.299 / 0.345$ & $0.99 / 1.15$ & 1.17 \\
\hline 16 & 1.75 & 0.47 & $745 / 600$ & 1.1155 & 0.693 & 0.281 & $0.305 / 0.353$ & $1.08 / 1.25$ & 1.26 \\
\hline 17 & 2.00 & 0.54 & 729 & 1.0427 & 0.707 & 0.264 & $0.312 / 0.361$ & $1.18 / 1.37$ & - \\
\hline 18 & 2.25 & 0.61 & $712 / 582$ & 0.9805 & 0.723 & 0.251 & $0.319 / 0.369$ & $1.27 / 1.47$ & 1.46 \\
\hline 19 & 2.50 & 0.67 & 693 & 0.9263 & 0.740 & 0.236 & $0.326 / 0.378$ & $1.38 / 1.60$ & - \\
\hline 20 & 3.00 & 0.81 & 650 & 0.8481 & 0.778 & 0.213 & $0.342 / 0.395$ & $1.60 / 1.85$ & - \\
\hline
\end{tabular}

\subsection{Sample CB-60}

Initial data (Table 4): $R_{1}=R_{2}=30 \mathrm{~mm}$ rollers, cycle life $N=1.5 \times 10^{7}$ at $\sigma_{\max }=1570 \mathrm{MPa}$, fracture depth $0.13-0.81 \mathrm{~mm}$, fatigue curve degree indicator $q=24$ (according to experimental data at five loading levels). Figure 7 shows the deep destruction of the sample as a result of contact stresses. Cracks under the surface of the sample are visible.

Table 4. Initial data for DCS accessing of sample CD-30

\begin{tabular}{cc}
\hline$H_{0}, \mathrm{HV}$ & 850 \\
$H_{K}, \mathrm{HV}$ & 260 \\
$H_{e}, \mathrm{HV}$ & 550 \\
$h_{0}, \mathrm{~mm}$ & 0.00 \\
$h_{t e}, \mathrm{~mm}$ & 1.37 \\
$h_{t}, \mathrm{~mm}$ & 2.60 \\
$b_{H}, \mathrm{~mm}$ & 0.420 \\
$\sigma_{k \max }, \mathrm{MPa}$ & 1570 \\
$k_{\min }$ & 1.670 \\
$k_{\max }$ & 2.003 \\
\hline
\end{tabular}




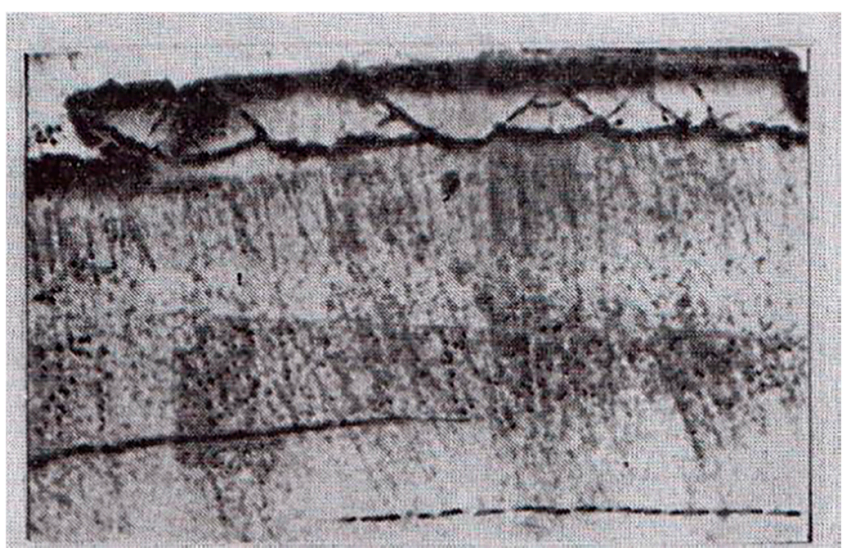

Figure 7. Cross microsection of sample CB-60.

Table 5. DCS indicators of sample CB-60.

\begin{tabular}{cccccccccc}
\hline No. & $z_{0}$ & $z$ & $H_{Z}(\mathbf{H V} / \mathbf{H B})$ & $\sigma_{i} / H_{Z}$ & $\chi$ & $\frac{\sigma_{e}}{\sigma_{k \max }}$ & $\begin{array}{c}\sigma_{K H e} / \sigma_{k \max } \\
\min / \mathbf{m a x}\end{array}$ & $\begin{array}{c}S_{K H e} / \sigma_{k \max } \\
\mathbf{m i n} / \mathbf{m a x}\end{array}$ & $\begin{array}{c}\sigma_{K H e} / \sigma_{k \max } \\
\left(\tau_{\max }\right)\end{array}$ \\
\hline 1 & 0.40 & 0.17 & $846 / 644$ & 0.9540 & 0.603 & 0.265 & $0.267 / 0.320$ & $1.01 / 1.21$ & 1.55 \\
2 & 0.50 & 0.21 & $844 / 644$ & 1.0051 & 0.605 & 0.284 & $0.268 / 0.322$ & $0.94 / 1.13$ & 1.47 \\
3 & 0.60 & 0.25 & 840 & 1.0347 & 0.608 & 0.299 & $0.270 / 0.324$ & $0.90 / 1.08$ & - \\
4 & 0.70 & 0.29 & $837 / 640$ & 1.0466 & 0.611 & 0.309 & $0.272 / 0.326$ & $0.88 / 1.06$ & 1.34 \\
5 & 0.80 & 0.34 & 830 & 1.0461 & 0.616 & 0.314 & $0.274 / 0.329$ & $0.87 / 1.05$ & - \\
6 & 0.90 & 0.38 & $826 / 635$ & 1.0350 & 0.62 & 0.314 & $0.277 / 0.332$ & $0.88 / 1.05$ & 1.34 \\
7 & 1.00 & 0.42 & 823 & 1.0188 & 0.624 & 0.314 & $0.280 / 0.335$ & $0.89 / 1.07$ & - \\
8 & 1.10 & 0.46 & $817 / 632$ & 0.9973 & 0.629 & 0.31 & $0.283 / 0.339$ & $0.91 / 1.09$ & 1.36 \\
9 & 1.20 & 0.50 & 808 & 0.9744 & 0.635 & 0.306 & $0.287 / 0.343$ & $0.94 / 1.12$ & - \\
10 & 1.50 & 0.63 & $786 / 615$ & 0.9036 & 0.655 & 0.289 & $0.299 / 0.358$ & $1.03 / 1.24$ & 1.52 \\
11 & 2.00 & 0.84 & 736 & 0.8066 & 0.701 & 0.262 & $0.324 / 0.388$ & $1.24 / 1.48$ & - \\
12 & 2.50 & 1.05 & $670 / 562$ & 0.7473 & 0.76 & 0.242 & $0.351 / 0.421$ & $1.45 / 1.74$ & 1.72 \\
13 & 3.00 & 1.26 & 593 & 0.7252 & 0.828 & 0.227 & $0.374 / 0.449$ & $1.65 / 1.98$ & - \\
14 & 3.50 & 1.47 & 510 & 0.7389 & 0.902 & 0.217 & $0.387 / 0.464$ & $1.75 / 2.10$ & - \\
15 & 4.00 & 1.68 & $428 / 398$ & 0.7565 & 0.975 & 0.201 & $0.383 / 0.460$ & $1.90 / 2.22$ & 1.68 \\
16 & 4.50 & 1.89 & $355 / 350$ & 0.7616 & 1 & 0.172 & $0.335 / 0.402$ & $1.94 / 2.32$ & 1.76 \\
17 & 5.00 & 2.10 & 300 & 0.7226 & 1 & 0.138 & $0.283 / 0.341$ & $2.05 / 2.44$ & - \\
\hline \multicolumn{7}{c}{} & \multicolumn{7}{c}{} & & & & & &
\end{tabular}

The graphs below show the DCS of the studied samples: Figure 8 shows that of sample CD-30, while Figure 9 shows that of sample CB-60, where (a) is the amplitude of the ratio of octahedral stresses to hardness and (b) is the current and permissible equivalent stress. Dashed lines show actual destruction zones.

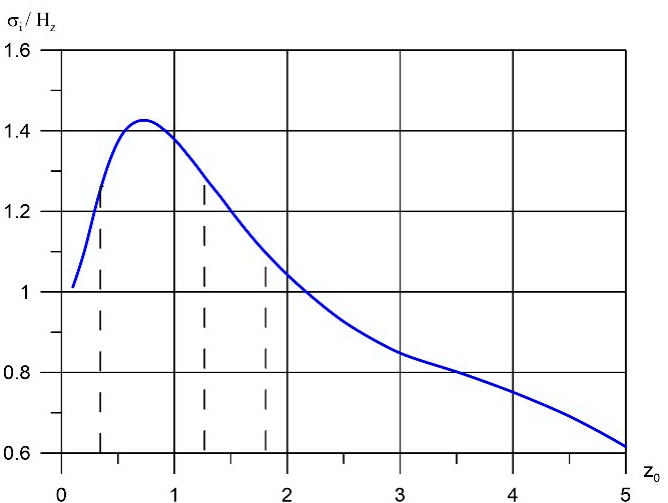

(a)

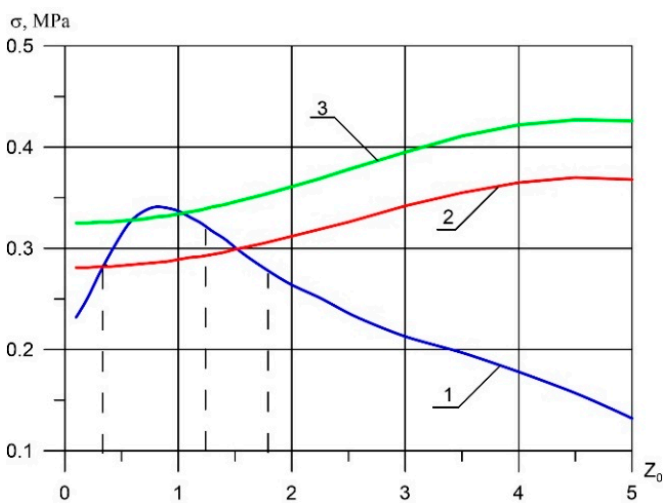

(b)

Figure 8. DCS CD-30 sample: (a) the amplitude of the ratio of octahedral stresses to hardness; (b) current and permissible equivalent stress: (1) $\sigma_{e}$ equivalent stress; (2) $\sigma_{H k e m i n}$ minimum allowable stress according to the DCS criterion; (3) $\sigma_{H k e m a x}$ maximum allowable stress according to the DCS criterion. 


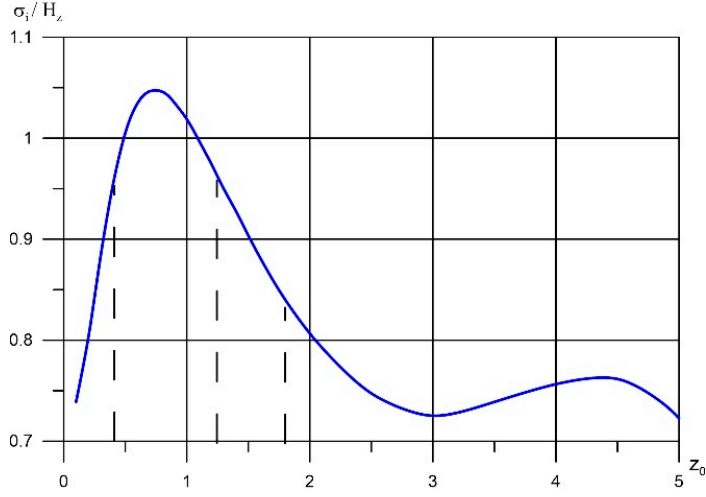

(a)

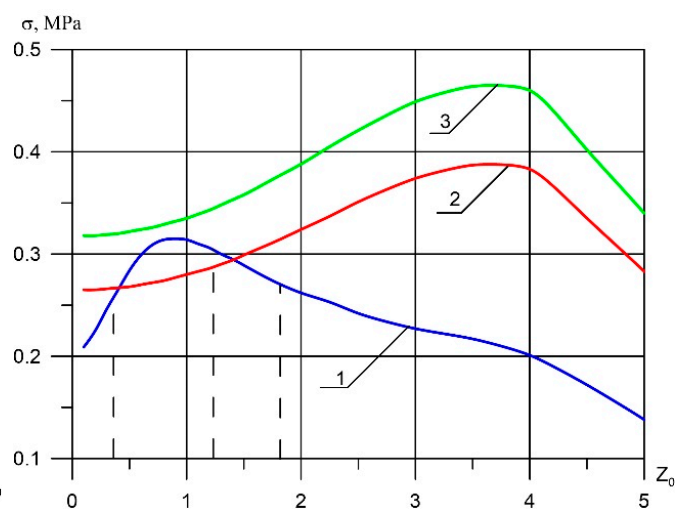

(b)

Figure 9. DCS CB-60 sample: (a) the amplitude of the ratio of octahedral stresses to hardness; (b) current and permissible equivalent stress: (1) $\sigma_{e}$ equivalent stress; (2) $\sigma_{H k e m i n}$ minimum allowable stress according to the DCS criterion; (3) $\sigma_{\text {Hkemax }}$ maximum allowable stress according to the DCS criterion.

The calculations showed important features of the CD-30 and CB-60 samples.

(1) For CD-30 samples, the depth of the crack initiating DCS of this sample is about $0.15 \mathrm{~mm}$ (Figure 6). The fracture zone is in the area of maximum material strength; the load capacity of the part is limited by the strength of the diffusion layer itself. The deep contact strength of the samples is not provided. It is necessary to introduce a safety factor according to the DCS criterion $S_{K H e} \geq 1.2$.

(2) The local maximum of the ratio $\sigma_{i} / H_{Z}$ is in good agreement with the average depth of contact fractures CD-30 samples. The presence of only one local maximum makes it possible to focus on the largest value of the coefficient $K_{2}$.

(3) The actual fracture area of the CD-30 samples corresponds to the predicted calculated depth interval.

(4) In the photograph of the microsection (Figure 7), the fracture depth in the effective zone reaches 0.45-0.50 mm, which is rather close to the predicted calculated one. But in the sublayer (in the depth interval $z=1.7-2.1 \mathrm{~mm}$ ), the main cracks were discovered in the stages coming before the branching. When testing the same samples at stress from $1668 \mathrm{MPa}$ and above, fracturing in the sublayer became faster.

(5) The graph of the ratio $\sigma_{i} / H_{Z}$ indicates the presence of two potentially dangerous areas: in the effective zone and in the sublayer. Outstripping were the destruction in the effective zone.

(6) The deep contact strength of the samples is not provided. It is necessary to introduce a safety factor by the DCS criterion $S_{K H e} \geq 1.32$.

\section{Conclusions}

(1) The proposed model, in most cases, gives a satisfactory quantitative assessment of the DCS over the entire depth of the layer. For sections of the sublayer adjacent to the core, the results converge, and at hardness below $400 \mathrm{HV}$, they coincide with those obtained by the Mises criterion.

(2) Most well-known DCS assessment methods are focused on the range of maximum equivalent stresses. Virtually no cases of the presence of a "second risk zone" are considered, in which DCS arises at depths with estimated safety factors $S_{K H e} \gg 1$. There is no explanation for this phenomenon from the point of view of existing models. However, qualitatively, it is a local relative decrease in the safety factor or by the appearance of the second maximum of the ratio of the amplitude value of the criterion stresses to hardness. This determines a preliminary check of potentially dangerous zones and layer thickness, which excludes the possibility of the appearance of a second zone or reduces (by up to 15\%) the allowable stresses. 
(3) This test, of course, requires information on the distribution of hardness over the entire thickness of the hardened layer. But Formula (7) is associated with widely regulated core hardness and total layer thickness, which most often shows high values of hardness in the transition zone. In our opinion, it is preferable to use dependence (8) with a reference point $H_{e}=50 \mathrm{HRC}(550 \mathrm{HV})$ for low alloy steels of general engineering purpose for cementation and for nitrocarburizing and cementation of heat-resistant steels $H_{e}=52 \mathrm{HRC}(610 \mathrm{HV})$.

(4) The basic number of cycles and indicators of the degree of endurance curve differ not only with surface and deep fractures but also with deep ones depending on the material structure, load level, defect nucleation region, etc., (a typical example is the considered experiments with C-120 rollers). At this stage, we can talk about the undesirability of the presence of layers with hardness higher than $800 \mathrm{HV}$ due to increasing embrittlement, reflected by a decrease in the value of the ductility parameter.

(5) It is very useful to adjust the allowable stresses by introducing a lowering coefficient of the structure, taking into account the presence of bainitic and carbide phases in the structure. In the considered model (1), its analog is used, $A$-the statistical parameter of defectiveness. The value of $A$ is averaged, and taking into account the actual structural features can lead to a refinement of this parameter or to the introduction of the corresponding coefficient in Equation (6).

(6) The results obtained make it possible to refine the parameters of deep contact strength substantially. Thus, the $S_{K H e}$ safety factor for nitriding is allowed up to 1.5 [21], while cementing carbon steels and alloyed with nickel content up to $1 \%, 1.5 \%$ and $1.3 \%$, respectively [6]. Since the contact stresses and the applied load are related by a cubic (or close to it) dependence, in the case of classical linear contact, the introduction of the $S_{\mathrm{KHe}}=1.5$ coefficient determines a decrease in the applied load by more than three times, and $S_{K H e}=1.3$ by 2.2 times. Calculations according to the presented model, in the presence of only one potentially dangerous zone, show the possibility for alloyed steels with nickel content up to $1 \%$ to be limited by the safety factor $S_{K H e} \leq 1.2$, which will increase the load capacity by $25-27 \%$.

Author Contributions: Conceptualization, B.M., N.O. and A.B.; methodology, N.O. and O.A.; software, L.K.; validation, N.O., A.B., L.K. and O.A.; formal analysis, N.O. and A.B.; investigation, A.B. and N.O.; resources, B.M., N.O. and O.A.; data curation, A.B. and L.K.; writing-original draft preparation, A.B., N.O. and L.K.; writing-review and editing, A.B., L.K., N.O., B.M. and O.A.; visualization, L.K. and A.B.; supervision, A.B. and N.O.; project administration, B.M., A.B. and O.A.; funding acquisition, B.M. and O.A. All authors have read and agreed to the published version of the manuscript.

Funding: This research was funded by Don State Technical University and by the Russian Foundation for Base Research (project 18-01-00715-a).

Acknowledgments: The authors would like to acknowledge the administration of the Don State Technical University for funding this article and using the experiment tool.

Conflicts of Interest: The authors declare no conflict of interest.

\section{References}

1. Gupta, K.; Jain, N.; Laubscher, R. Advanced Gear Manufacturing and Finishing; Academic Press: Cambridge, MA, USA, 2017; 240p. [CrossRef]

2. Fujita, K.; Yoshida, A. Surface failure of soft and surface-hardened steel rollers in rolling contact. Wear 1979, 55, 27-39. [CrossRef]

3. Tobie, T.; Hippenstiel, F.; Mohrbacher, H. Optimizing Gear Performance by Alloy Modification of Carburizing Steels. Metals 2017, 7, 415. [CrossRef]

4. Beskopylny, A.; Onishkov, N.; Korotkin, V. Assessment of the Fatigue Durability of the Rolling Contact. In International Scientific Conference Energy Management of Municipal Transportation Facilities and Transport EMMFT 2017; Advances in Intelligent Systems and Computing; Murgul, V., Popovic, Z., Eds.; Springer: Cham, Switzerland, 2018; Volume 692, pp. 184-191. [CrossRef]

5. Leng, X.; Chen, Q.; Shao, E. Initiation and propagation of case crushing cracks in rolling contact fatigue. Wear 1988, 122, 33-43. [CrossRef] 
6. Tsushima, N.; Maeda, K.; Nakashima, N. Rolling contact fatigue life of various kinds of high-hardness steels and influence of material factors on rolling contact fatigue life. In Effect of Steel Manufacturing Processes on the Quality of Bearing Steels; Hoo, J., Ed.; ASTM International: West Conshohocken, PA, USA, 1988; pp. $132-148$. [CrossRef]

7. GOST 21354-87. Cylindrical Evolvent Gears of External Engagement. Strength Calculation; Publishing House of Standards: Moscow, Russia, 1988; 125p, Available online: http://docs.cntd.ru/document/1200011855 (accessed on 2 April 2020).

8. Biserova-Tahchieva, A.; Cabrera, J.; Llorca-Isern, N. Study of the Thermochemical Surface Treatment Effect on the Phase Precipitation and Degradation Behaviour of DSS and SDSS. Materials 2020, 13, 165. [CrossRef]

9. Amanov, A.; Darisuren, S.; Pyun, Y. Bearings Downsizing by Strength Enhancement and Service Life Extension. Materials 2018, 11, 1662. [CrossRef]

10. Sugimoto, K.; Hojo, T.; Mizuno, Y. Effects of Vacuum-Carburizing Conditions on Surface-Hardened Layer Properties of Transformation-Induced Plasticity-Aided Martensitic Steel. Metals 2017, 7, 301. [CrossRef]

11. Li, B.; Li, C.; Wang, Y.; Jin, X. Effect of Cryogenic Treatment on Microstructure and Wear Resistance of Carburized 20CrNi2MoV Steel. Metals 2018, 8, 808. [CrossRef]

12. Li, G.; Li, C.; Xing, Z.; Wang, H.; Huang, Y.; Guo, W.; Liu, H. Study of the Catalytic Strengthening of a Vacuum Carburized Layer on Alloy Steel by Rare Earth Pre-Implantation. Materials 2019, 12, 3420. [CrossRef]

13. Liu, C.-P.; Zhao, X.-J.; Liu, P.-T.; Pan, J.-Z.; Ren, R.-M. Influence of Contact Stress on Surface Microstructure and Wear Property of D2/U71Mn Wheel-Rail Material. Materials 2019, 12, 3268. [CrossRef]

14. Kvryan, A.; Efaw, C.; Higginbotham, K.; Maryon, O.; Davis, P.; Graugnard, E.; Trivedi, H.; Hurley, M. Corrosion Initiation and Propagation on Carburized Martensitic Stainless Steel Surfaces Studied via Advanced Scanning Probe Microscopy. Materials 2019, 12, 940. [CrossRef]

15. Borgioli, F. From Austenitic Stainless Steel to Expanded Austenite-S Phase: Formation, Characteristics and Properties of an Elusive Metastable Phase. Metals 2020, 10, 187. [CrossRef]

16. Li, Z.; Illing, C.; Heuer, A.; Ernst, F. Low-Temperature Carburization of AL-6XN Enabled by Provisional Passivation. Metals 2018, 8, 997. [CrossRef]

17. Adachi, S.; Ueda, N. Wear and Corrosion Properties of Cold-Sprayed AISI 316L Coatings Treated by Combined Plasma Carburizing and Nitriding at Low Temperature. Coatings 2018, 8, 456. [CrossRef]

18. Chapurkin, V.V.; Tesker, E.I.; Aseev, N.; Tesker, S.Y. Laser treatment of polymer-coated steel components. In Proceedings of the SPIE 2713, Fifth International Conference on Industrial Lasers and Laser Applications '95, Shatura, Moscow Region, Russia, 24-26 June 1995. [CrossRef]

19. Tesker, E.I. Improvement of Methods of Design and Analysis of Load-Carrying Capacity of Case-Hardened Cageless Bearing Units for Power Drives of Mobile Machines. In New Approaches to Gear Design and Production. Mechanisms and Machine Science; Goldfarb, V., Trubachev, E., Barmina, N., Eds.; Springer: Cham, Switzerland, 2020; Volume 81, pp. 461-471. [CrossRef]

20. Tesker, E.; Tesker, S. Modern Methods of Calculation and Increasing the Load-Carrying Capacity of Surface-Hardened Gears of Transmissions and Drives. In Theory and Practice of Gearing and Transmissions. Mechanisms and Machine Science; Goldfarb, V., Barmina, N., Eds.; Springer: Cham, Switzerland, 2016; Volume 34, pp. 233-261. [CrossRef]

21. Korotkin, V.; Onishkov, N.; Gol'tsev, A. Estimating the deep contact strength of evolvent gear transmission with surface-hardened teeth. Russ. Eng. Res. 2008, 28, 407-413. [CrossRef]

22. Galper, R. Deep contact strength of the surface hardened working surface. In Increasing the Bearing Capacity of a Mechanical Drive; Kudryavtsev, V.N., Ed.; Mechanical Engineering: Moscow, Russia, 1973; pp. 82-88.

23. Rudenko, S.; Val'ko, A. Contact Fatigue of Transmission Gears of Energy-Intensive Machines; Belaruskaya Navuka: Minsk, Belarus, 2014; 126p. (In Russian)

24. Rudenko, S.; Val'ko, A. Contact Fatigue Resistance of Carburized Gears from Chromium-Nickel Steels. Met. Sci. Heat Treat. 2017, 59, 60-64. [CrossRef]

25. Wolkenstein, R. Die Hartentiefe an Zahnradern. Teil 1. Zahnflanke-Prinzip des Verfahrens. MaschinenweltElectrotechn. 1979, 5, 116-122.

26. Elkholy, A. Case depth requirements in carburized gears. Wear 1983, 88, 233-244. [CrossRef]

27. Korotkin, V.I.; Onishkov, N.P. Novikov gearing: Achievements and ways to further development. Russ. Eng. Res. 2007, 27, 217-219. [CrossRef] 
28. Beskopylny, A.; Meskhi, B.; Onishkov, N.; Korotkin, V. Strength Characteristics Analysis of Structurally Inhomogeneous Steel Gears. In VIII International Scientific Siberian Transport Forum. TransSiberia 2019; Advances in Intelligent Systems and Computing; Popovic, Z., Manakov, A., Breskich, V., Eds.; Springer: Cham, Switzerland, 2020; Volume 1115, pp. 894-903. [CrossRef]

29. Beskopylny, A.; Meskhi, B.; Onishkov, N.; Korotkin, V. Limit-State Criteria and Their Use in Conditions of the Significant Structural Heterogeneity of the Gear Steel. In VIII International Scientific Siberian Transport Forum. TransSiberia 2019; Advances in Intelligent Systems and Computing; Popovic, Z., Manakov, A., Breskich, V., Eds.; Springer: Cham, Switzerland, 2020; Volume 1115, pp. 904-912. [CrossRef]

30. Zinchenko, V.M. Surface engineering: A way to provide maximum properties in articles. Met. Sci. Heat Treat. 1999, 41, 292-300. [CrossRef]

31. Voskamp, A.P. Material Response to Rolling Contact Loading. J. Tribol. 1985, 107, 359. [CrossRef]

32. Broszeit, E.; Zwirlein, O. Internal Stresses and Their Influence on Material Stresses in Hertzian Contacts. Calculations with Different Stress Hypotheses. J. Tribol. 1986, 108, 387-393. [CrossRef]

33. Pisarenko, G.S.; Lebedev, A.A. Deformation and Strength of Materials under Complex Stress Conditions; Naukova Dumka: Kiev, Ukraine, 1976. (In Russian)

34. Pisarenko, G.S.; Koval'chuk, B.I.; Lebedev, A.A. Principles of deformation of carbon steel with complex loading under normal conditions and at low temperatures. Strength Mater. 1972, 4, 134-139. [CrossRef]

35. Shapochkin, V.I.; Zaitseva, I.D.; Burenkóva, O.S. Resistance to contact fatigue of heavy-duty gear wheels made of steel 20KhN3A and hardened by thermochemical treatment. Met. Sci. Heat Treat. 1987, 29, 333-339. [CrossRef]

36. Yatsenko, V.K.; Kostenko, N.A. Criteria for evaluating the surface strain-hardening of machine parts. Strength Mater. 1985, 17, 325-328. [CrossRef]

37. Grum, J. How to Select Induction Surface Hardening and Finished Grinding Conditions in Order to Ensure High Compressive Residual Stresses on Machine Parts Surface. Mater. Sci. Forum 2003, 426-432, 2599-2604. [CrossRef]

38. Yoshida, A.; Fujita, K.; Kanehara, T.; Ota, K. Effect of Case Depth on Fatigue Strength of Case-Hardened Gear. Bull. JSME 1986, 29, 228-234. [CrossRef]

(C) 2020 by the authors. Licensee MDPI, Basel, Switzerland. This article is an open access article distributed under the terms and conditions of the Creative Commons Attribution (CC BY) license (http://creativecommons.org/licenses/by/4.0/). 